\title{
Plastic Changes of Calcitonin Gene-Related Peptide in Morphine Tolerance: Behavioral and Immunohistochemical Study in Rats
}

\author{
Xiang Zhou, Jin-Ju Li, and Long-Chuan Yu* \\ Neurobiology Laboratory, College of Life Sciences, Center for Brain and Cognitive Science and National \\ Laboratory of Biomembrane and Membrane Biotechnology, Peking University, Beijing, \\ People's Republic of China
}

The present study was undertaken to investigate the plasticity of calcitonin gene-related peptide (CGRP) in antinociception after morphine tolerance in rats. The hindpaw withdrawal latencies (HWLs) to both thermal and mechanical stimulation increased significantly after intracerebroventricular injection of $2.5 \mathrm{nmol}$ of CGRP in opioid-naive rats, indicating that CGRP produces an antinociceptive effect in the brain. Furthermore, there was an antinociceptive effect after intracerebroventricular injection of $2.5 \mathrm{nmol}$ of CGRP in morphine-tolerant rats. Interestingly, the antinociceptive effect induced by intracerebroventricular injection of CGRP was lower in morphine-tolerant rats than that in opioid-naive rats at the same dose. At the same time, there was downregulation of CGRP-like immunoreactivity in both lateral septal nucleus and central nucleus of amygdala tested by immunohistochemical methods, whereas no significant changes were observed in arcuate nucleus of hypothalamus and periaqueductal gray after morphine treatment in rats. The present study demonstrates plastic changes in both CGRP-induced antinociception and CGRP-like immunoreactivity in rat brain after morphine tolerance, suggesting that CGRP may play an important role in morphine tolerance. $\odot 2003$ Wiley-Liss, Inc.

Key words: antinociception; calcitonin gene-related peptide; CGRP-like immunoreactivity; hindpaw withdrawal latency; morphine tolerance

Calcitonin gene-related peptide (CGRP) is a 37amino acid peptide produced by alternative splicing of mRNA from the calcitonin gene and is distributed widely in the central nervous system (CNS) with multiple physiological functions (van Rossum et al., 1997). Studies in our laboratory demonstrated that CGRP was involved in the modulation of nociception in the spinal cord ( $\mathrm{Yu}$ et al., 1994, 1996a,b). It has been reported that intracerebroventricular injection of CGRP also resulted in antinociceptive effects (Pecile et al., 1987; Welch et al., 1988; Candeletti and Ferri, 1990). Furthermore, recent studies in our laboratory demonstrated that CGRP plays an antinociceptive role in some important structures of pain modulation in the rat brain (Huang et al., 2000; Xu et al., 2000, 2003; Li et al., 2001; Yu et al., 2003).

(c) 2003 Wiley-Liss, Inc.
A complex relationship between CGRP and opioids has been suggested. Intrathecal injection of CGRP attenuated analgesia induced by either $\mu$ or $\delta$ opioid agonists (van Rossum et al., 1997), and endogenous opioid peptides were involved in antinociception induced by intracerebroventricular injection of CGRP (Welch et al., 1988). Although, at the spinal levels, there was a lack of effect of acute injection of morphine on CGRP release (Morton and Hutchison, 1990; Collin et al., 1993), it has been demonstrated that there was a close interaction between CGRP release and stimulation of different opioid receptors (Collin et al., 1993; Ballet et al., 1998; Bao et al., 2003). It has also been assumed that a tonic opioid control of CGRP levels existed in the brain (Welch et al., 1992).

Recent studies have shown that the development of morphine tolerance was inhibited by either CGRP8-37 (Menard et al., 1996; Powell et al., 2000), a peptide antagonist of the CGRP receptor, or BIBN4096BS (Powell et al., 2000), a potent nonpeptide antagonist of the CGRP receptor (Doods et al., 2000). Another study showed that CGRP suppressed the development of rapid tolerance to morphine in a dose-dependent manner (Azarov et al., 1995). The above results implicated a possible involvement of CGRP during morphine tolerance. Data were not always consistent, however, as CGRP $\mathrm{P}^{-/-}$mice did not show changes in morphine tolerance (Salmon et al., 2001). Moreover, reported data were conflicting concerning the changes of CGRP-like immunoreactivity at the spinal levels during the development of morphine tolerance (Nylander et al., 1991; Welch et al., 1992; Belanger et al., 2002; Gardell et al., 2002). A few studies focused on possible changes of CGRP-like immunoreactivity at the supraspinal levels during morphine tolerance, and yielded different results in different regions (Tiong et al., 1992;

Contract grant sponsor: National Natural Science Foundation of China (NSFC); Contract grant sponsor: Hui-Chun Chin and Tsung-Dao Lee Chinese Undergraduate Research Endowment.

^Correspondence to: L.-C. Yu, Department of Physiology, College of Life Sciences, Peking University, Beijing 100871, China. E-mail: yulc@pku.edu.cn Received 5 May 2003; Revised 3 July 2003; Accepted 4 July 2003 
Welch et al., 1992). The present study was undertaken to investigate the plastic changes of CGRP in rat brain after morphine tolerance using behavioral and immunohistochemical methods.

\section{MATERIALS AND METHODS}

\section{Animal Preparation}

Experiments were carried out on freely moving male Wistar rats weighing 220 -250 g (Experimental Animal Center of Academy of Military Medical Sciences, Beijing, China). The rats were housed in cages with free access to food and water, and maintained in a room temperature of $24 \pm 2^{\circ} \mathrm{C}$ with a normal day/night cycle. All experiments were conducted according to the guidelines of the International Association for the Study of Pain (Zimmermann, 1983) and every effort was made to minimize animal suffering and the number of animal used.

\section{Chemicals}

Solutions for intracerebroventricular injection were prepared with sterilized saline $(0.9 \%)$, each with a volume of $5 \mu \mathrm{l}$ of either $2.5 \mathrm{nmol}$ of CGRP (rat-CGRP; Tocris Cookson Ltd., Bristol, UK) or $10 \mu \mathrm{g}$ of morphine (morphine $\mathrm{HCl}$; Shenyang First Pharmaceutical Factory, China). The following chemicals were used in the immunohistochemistry: ABC Elite kit (Vector Laboratories, Burlingame, CA), biotinylated goat anti-rabbit IgG (Vector), 3, 3'-diaminobenzidine tetra-HCl (DAB; Sigma, St. Louis, MO), and rabbit anti-CGRP serum (Phoenix Pharmaceuticals, Belmont, CA).

\section{Nociceptive Tests}

Hindpaw withdrawal latencies (HWLs) during thermal and mechanical stimulation were measured as described previously (Yu et al., 1996a,b). Briefly, the entire ventral surface of the rat hindpaw was placed manually on a hot plate, which was maintained at a temperature of $52^{\circ} \mathrm{C}\left(51.8-52.4^{\circ} \mathrm{C}\right)$. The time to hindpaw withdrawal was measured in seconds and referred to as HWL to thermal stimulation. The Randall Selitto Test (Ugo Basile, Type 7200, Italy) was used to assess the HWL to mechanical stimulation. A wedge-shaped pusher at a loading rate of $30 \mathrm{~g} / \mathrm{sec}$ was applied to the dorsal surface of the manually handled hindpaw. The latency required to initiate the withdrawal response was assessed and expressed in seconds. The average HWL value obtained before intracerebroventricular injection was regarded as the basal HWL. Intracerebroventricular injection was then carried out over 1 min. HWLs recorded during subsequent experiments were expressed as percent change of the basal level for each rat (\% change of the HWL). Each rat was tested with both types of stimulation. All measurements of HWL to thermal and mechanical stimulation on both hindpaws were completed within 2 min and intervals between stimulation were long enough for rats to recover from stress. A cut-off limit of $15 \mathrm{sec}$ per stimulation was set up to avoid tissue damage. All rats were accustomed to test conditions for 5 days before the starting of the experiment to minimize stress induced by handling.

\section{Intracerebroventricular Injection}

Animals were anesthetized by intraperitoneal (i.p.) sodium pentobarbital $(50 \mathrm{mg} / \mathrm{kg})$ and mounted on a stereotaxic instru- ment. A stainless steel guide cannula $(0.8 \mathrm{~mm}$ outer diameter $)$ was directed to the lateral cerebral ventricle (AP $-0.9, \mathrm{~L} 1.5, \mathrm{~V}$ $3.6 \mathrm{~mm}$ from surface of the skull; AP, anterior $(+)$ or posterior $(-)$ to bregma; L, lateral to midline; $\mathrm{V}$, ventral to the surface of skull) according to Paxinos and Watson (1998) and was fixed to the skull by dental acrylic. On the experimentation day, a stainless steel needle $(0.4 \mathrm{~mm}$ diameter) was inserted directly into the guide cannula, with $1.5 \mathrm{~mm}$ beyond the cannula tip, and $5 \mu l$ of solution was infused into the lateral cerebral ventricle over $1 \mathrm{~min}$.

\section{Tolerance Induction}

Rats in the morphine treatment group $(n=8)$ received intracerebroventricular injections of $10 \mu \mathrm{g} / 5 \mu \mathrm{l}$ of morphine twice daily (at 10:00 AM and 10:00 PM) for 7 days. For assessment of tolerance, the antinociceptive effect of morphine was determined daily $30 \mathrm{~min}$ after the first injection, and was compared to the effect of morphine on the first day. Morphine-induced increases in HWL decreased in the 2-4 days after morphine treatment, and morphine tolerance appeared on Day 7 . The rats were then administrated the drugs designed $6 \mathrm{hr}$ after last injection of morphine on Day 7.

\section{Immunohistochemistry}

Opioid-naive rats $(n=3)$ and rats with morphine tolerance ( $n=3 ; 6 \mathrm{hr}$ after last injection of morphine) were used in the immunohistochemical experiments. Rats were anesthetized with sodium pentobarbital $(50 \mathrm{mg} / \mathrm{kg}$, i.p.) and euthanized by transcardiac perfusion (saline wash, followed by $4 \%$ paraformaldehyde in $0.1 \mathrm{M}$ phosphate buffer, $\mathrm{pH}$ 7.4). The rat brains were removed and postfixed in the above solution for $3 \mathrm{hr}$, and then stored in $0.1 \mathrm{M}$ phosphate-buffered saline (PBS) containing 30\% sucrose for at least $24 \mathrm{hr}$ for cryoprotection. Frozen sections were cut with a freezing microtome at $35 \mu \mathrm{m}$ and collected for floating immunostaining.

Immunohistochemistry was carried out using an avidinbiotin complex $(\mathrm{ABC})$ Elite kit. Sections were preincubated for $30 \mathrm{~min}$ in PBS-Triton (0.01 M PBS, pH 7.4, plus $0.3 \%$ Triton $\mathrm{X}-100$ ), supplemented with $10 \%$ normal goat serum at room temperature. Sections were then incubated with rabbit antiCGRP serum, diluted 1:1,000 with PBS-Triton plus 1\% goat serum, for $36 \mathrm{hr}$ at $4^{\circ} \mathrm{C}$. All washes and subsequent incubations were carried out at room temperature: three 5-min washes in PBS-Triton, one 1-hr incubation in the secondary antibody of biotinylated goat anti-rabbit IgG $(50 \mu \mathrm{l} / 10 \mathrm{ml}$ diluent of PBSTriton), three 5-min washes in PBS-Triton, one 30-min incubation in $0.3 \% \mathrm{H}_{2} \mathrm{O}_{2}$, three 5-min washes in PBS-Triton, one 1-hr incubation in the avidin-biotin-peroxidase complex (50 $\mu \mathrm{l} / 5 \mathrm{ml}$ diluent of PBS-Triton), and three 5 -min washes in PBS-Triton. Finally, the sections were stained with DAB as the chromogen according to standard protocol $(0.05 \% \mathrm{DAB}$ in $0.01 \mathrm{M}$ PBS plus $0.3 \% \mathrm{H}_{2} \mathrm{O}_{2}$ ) for $5 \mathrm{~min}$ at room temperature and then washed twice for $5 \mathrm{~min}$ in $0.01 \mathrm{M}$ Tris- $\mathrm{HCl}$ solution. Control incubations with primary antiserum omitted were included and resulted in a lack of specific staining (data not shown).

Digitized images of sections in designated regions were captured at a resolution of $768 \times 534$ pixels with a high resolution CCD camera (JVC TK-C1380/TK-C1381). The Image $\mathrm{J}$ analysis package (NIH) was used to quantify changes in 

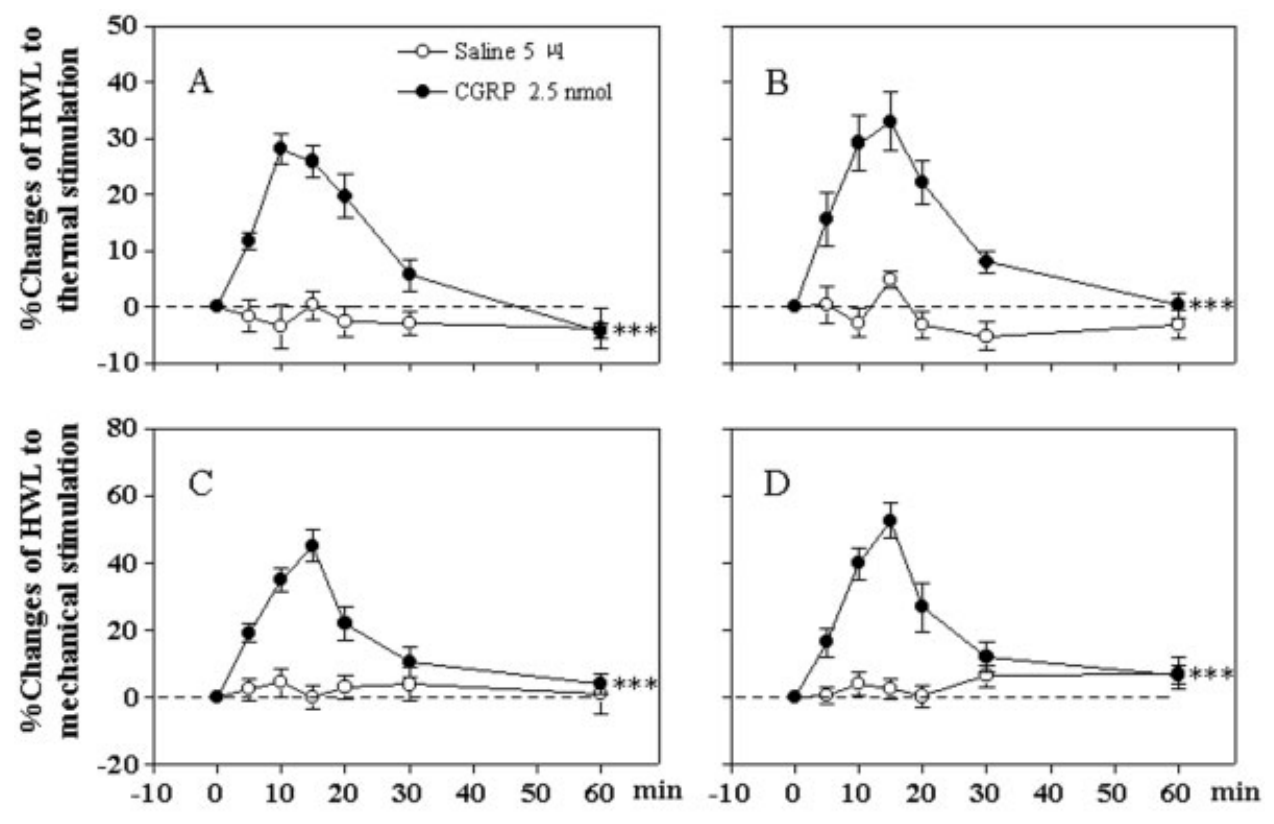

Fig. 1. Effects of intracerebroventricular injection of $2.5 \mathrm{nmol}$ of CGRP on HWLs to thermal $(\mathbf{A , B})$ and mechanical stimulation $(\mathbf{C}, \mathbf{D})$ in opioid-naive rats. HWL of left hindpaw shown in A and C; HWL of right hindpaw shown in $\mathrm{B}$ and D. Data are presented as mean \pm SEM. Statistical difference between groups was determined by two-way ANOVA, ${ }^{\star} P<0.05,{ }^{\star} \star P P<0.01$, and $\star \star \star P<0.001$ compared to control group. CGRP, calcitonin gene-related peptide; HWL, hindpaw withdrawal latency. immunoreactivity and gray value was applied as described previously (Wu et al., 1999). Six sections were selected randomly from each region in each rat and all sections from one region were tested in the same conditions. For each different region, all images were first converted into 8-bit resolution, in which pixels could have absolute gray values between 0 (pure black) and 255 (pure white). A standardized rectangle was then positioned over the designated area of morphine-tolerant rats and the mean gray value (MGV) of the area was calculated; the same box was positioned over the corresponding position of opioidnaive rats and the $\mathrm{MGV}$ of the area was again calculated. For each region of interest, the average $\mathrm{MGV}$ value from six sections of each rat was determined as result, and the mean \pm SEM of the gray value was obtained from each group.

\section{Statistical Analysis}

Data from nociceptive tests were presented as mean \pm SEM. Statistical differences between groups were determined by two-way analysis of variance (ANOVA) for repeated measurements in behavioral experiments and by Student's two-tailed $t$-test in immunohistochemical results. ${ }^{*} P<0.05, \star \star P<0.01$, and $\star \star \star P<0.001$ were considered significant differences.

\section{RESULTS}

\section{Antinociceptive Effect of Intracerebroventricular Injection of CGRP in Opioid-Naive Rats}

Two groups of opioid-naive rats received intracerebroventricular injections of $2.5 \mathrm{nmol}$ of CGRP $(n=8)$, or $5 \mu \mathrm{l}$ of $0.9 \%$ saline as a control $(n=8)$. Results are shown in Figure 1. Compared to the control group, the HWL increased significantly after intracerebroventricular administration of $2.5 \mathrm{nmol}$ CGRP (thermal test: $F_{\text {left/left }}=$ 47.44, $P<0.001 ; F_{\text {right } / \text { right }}=33.49, P<0.001$; mechanical test: $F_{\text {left/left }} \stackrel{=}{=} 28.82, P<0.001 ; F_{\text {right } / \text { right }}=$ 41.77, $P<0.001)$. The effect of intracerebroventricular administration of CGRP lasted about $30 \mathrm{~min}$ after the injection.

\section{Antinociceptive Effect of Intracerebroventricular Injection of CGRP in Morphine-Tolerant Rats}

Rats in the morphine treatment group $(n=8)$ received intracerebroventricular injection of $10 \mu \mathrm{g} / 5 \mu \mathrm{l}$ of morphine twice daily. The antinociceptive effect of morphine at 30 min after first injection daily was compared to the effect of morphine on the first day. The process of morphine tolerance is shown in Figure 2.

Two groups of rats with morphine tolerance received intracerebroventricular injection of $2.5 \mathrm{nmol}$ of CGRP $(n=8)$, or $5 \mu$ l of $0.9 \%$ saline as a control $(n=8)$. The results are shown in Figure 3. Compared to the control group, the HWL increased significantly after intracerebroventricular administration of $2.5 \mathrm{nmol}$ of CGRP (thermal test: $F_{\text {left/left }}=11.41, P<0.01 ; F_{\text {right }}$ / right $=6.99, P<0.05$; mechanical test: $F_{\text {left } / \text { left }}=7.84$, $\left.P<0.05 ; F_{\text {right } / \text { right }}=26.06, P<0.001\right)$.

\section{Change of Antinociceptive Effect Induced by Intracerebroventricular Injection of CGRP After Morphine Tolerance}

Results are shown in Figure 4. Compared to the antinociceptive effect of CGRP in opioid-naive rats, the HWL to both thermal and mechanical stimulation attenuated significantly in rats with morphine tolerance (thermal test: $F_{\text {left } / \text { left }}=5.61, P<0.05 ; F_{\text {right } / \text { right }}=4.93, P<$ 0.05; mechanical test: $F_{\text {left/left }}=12.20, P<0.01 ; F_{\text {right } /}$ right $=14.37, P<0.001)$.

\section{Changes of CGRP-Like Immunoreactivity in Rat Brain After Morphine Tolerance}

Large amounts of CGRP-like immunoreactive fibers were found in the lateral septal nucleus (LS) and central 
Fig. 2. The process of morphine tolerance after intracerebroventricular injection of $10 \mu \mathrm{g} / 5 \mu \mathrm{l}$ of morphine. A,B: HWL to thermal stimulation. C,D: HWL to mechanical stimulation. HWL of left hindpaw shown in A and C; HWL of right hindpaw shown in $\mathrm{B}$ and D. Data are presented as mean \pm SEM. HWL, hindpaw withdrawal latency.
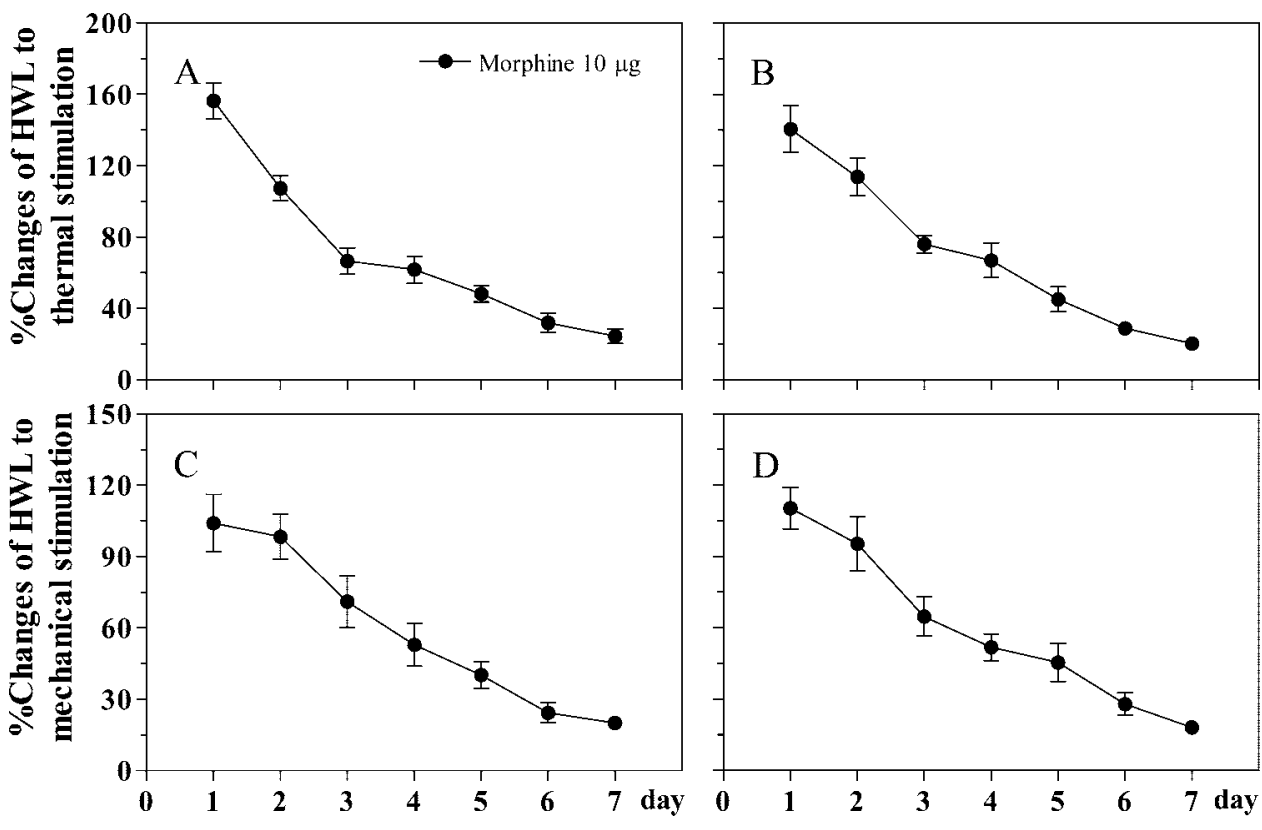

nucleus of amygdala (CeA), whereas moderate CGRPlike immunoreactive fibers were found in the arcuate nucleus (ARC) of hypothalamus and faint fibers in periaqueductal gray $(\mathrm{PAG})$ in opioid-naive rats, as shown in Figure 5 (A, C, E, and G, respectively). Quantification of the gray value of CGRP immunoreactivity were conducted using a 256-level gray scale, where a high gray value represents low immunoreactivity. The results illustrate marked decreases in CGRP-like immunoreactivity in both LS $(t=-3.20, P<0.05, n=3$; Figs. $5 \mathrm{~B}$ and 6$)$ and CeA $(t=-3.59, P<0.05, n=3$; Figs. 5D and 6$)$, whereas no significant changes were observed in the ARC of hypothalamus $(t=1.84, P=0.21, n=3$; Figs. 5F and 6) and PAG $(t=-1.36, P=0.26, n=3$; Figs. $5 \mathrm{H}$ and 6) after morphine tolerance in rats.

\section{DISCUSSION}

Previous study had shown that CGRP was effective in enhancing response latencies only at the highest dose, $10 \mu \mathrm{g}$ (about $2.5 \mathrm{nmol}$ )/rat (Pecile et al., 1987); therefore, the same dose was used in our research. The present study demonstrated that HWLs to both thermal and mechanical stimulation increased significantly after intracerebroventricular injection of $2.5 \mathrm{nmol}$ of CGRP in opioid-naive
Fig. 3. Effects of intracerebroventricular injection of $2.5 \mathrm{nmol}$ of CGRP on HWLs to thermal $(\mathbf{A , B})$ and mechanical stimulation $(\mathbf{C}, \mathbf{D})$ in rats with morphine tolerance. HWL of left hindpaw shown in $A$ and $C$; HWL of right hindpaw shown in B and D. Data are presented as mean \pm SEM. Statistical difference between groups was determined by twoway ANOVA, ${ }^{\star} P<0.05, \star \star P<0.01$, and $\star \star \star P<0.001$ compared to control group. CGRP, calcitonin gene-related peptide; HWL, hindpaw withdrawal latency.
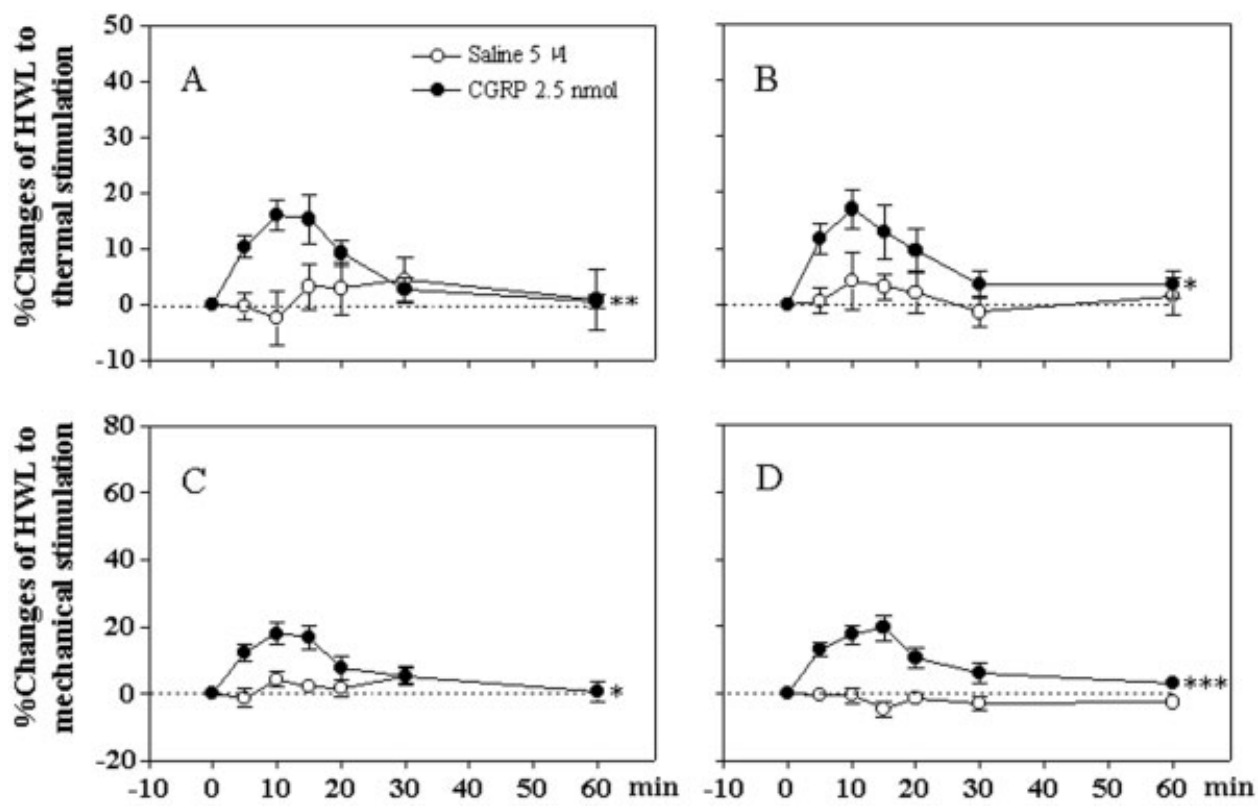

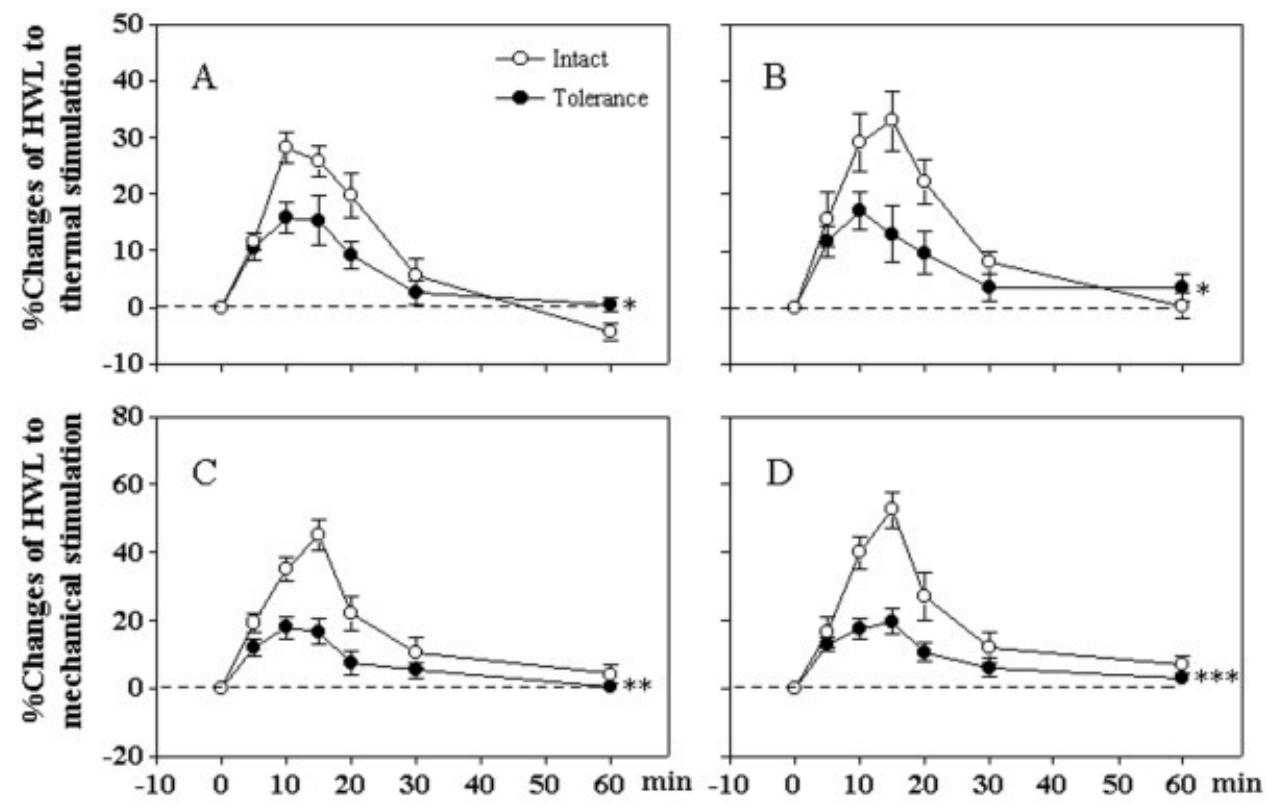

Fig. 4. Comparison of the antinociceptive effects of intracerebroventricular injection of $2.5 \mathrm{nmol}$ of CGRP on HWLs to thermal $(\mathbf{A}, \mathbf{B})$ and mechanical stimulation $(\mathbf{C}, \mathbf{D})$ in opioid-naive rats and rats with morphine tolerance. HWL of left hindpaw shown in A and C; HWL of right hindpaw shown in $\mathrm{B}$ and $\mathrm{D}$. Data are presented as mean \pm SEM. Statistical difference between groups was determined by two-way ANOVA, ${ }^{\star} P<$ $0.05, \star \star P \quad 10.01$, and $\star \star \star P<0.001$ compared to control group. CGRP, calcitonin gene-related peptide; HWL, hindpaw withdrawal latency. rats, indicating that CGRP produces an antinociceptive effect in the brain. Furthermore, there was also an antinociceptive effect after intracerebroventricular injection of $2.5 \mathrm{nmol}$ CGRP in morphine-tolerant rats. Interestingly, the antinociceptive effect induced by intracerebroventricular injection of CGRP was lower in morphine-tolerant rats than that in opioid-naive rats at the same dose. At the same time, there were downregulations in CGRP-like immunoreactivity in both LS and CeA as tested by immunohistochemical methods, whereas no significant changes were observed in the ARC of hypothalamus and PAG after morphine treatment in rats.

The involvement of CGRP in modulation of nociception at the spinal levels has been demonstrated by previous studies in our laboratory (Yu et al., 1994, 1996a,b). Furthermore, recent studies in our laboratory found that the antinociceptive effects of CGRP were mediated through the CGRP1 receptor in some important structures of the brain (Huang et al., 2000; Xu et al., 2000, 2003; Li et al., 2001; Yu et al., 2003). Our results also showed that intracerebroventricular injection of 2.5 nmol of CGRP produced an antinociceptive effect to both thermal and mechanical stimulation, which was consistent with previous results (Pecile et al., 1987; Welch et al., 1988; Candeletti and Ferri, 1990). The above studies indicated a possible role of CGRP in transmission and/or modulation of nociceptive information in the rat brain. Interestingly, our results found that intracerebroventricular injection of $2.5 \mathrm{nmol}$ of CGRP also produced an antinociceptive effect to both thermal and mechanical stimulation in morphine-tolerant rats, indicating that CGRP produces an antinociceptive effect at the supraspinal levels in rats with morphine tolerance. It is interesting to note, however, that the antinociceptive effect of CGRP in the brain was lower in morphine-tolerant rats than that in opioid-naive rats, suggesting plastic changes in antino- ciception induced by CGRP during the development of morphine tolerance.

Studies in our laboratory have reported that antinociception induced by CGRP was attenuated after injection of naloxone in nucleus raphe magnus (Huang et al., 2000) and in CeA (Xu et al., 2003). Welch et al. (1988) also demonstrated that CGRP produced naloxone-reversible antinociception after intracerebroventricular injection, indicating an involvement of endogenous opioid peptides in CGRP-induced antinociception. Furthermore, an opioid pathway involved in antinociception induced by CGRP has been reported in our laboratory: CGRP activated met-enkephalinergic neurons, which project from CeA to $\mathrm{PAG}$, producing an antinociceptive effect in rats (Xu et al., 2003). The above results suggest strongly that there is a relation between the CGRP and opioid systems in the brain. Although the underlying mechanisms for opioid tolerance remain unclear, early adaptive processes, including receptor phosphorylation, downregulation, or both, G-protein uncoupling, and adenylyl cyclase superactivation, have been suggested to be crucial to development of opioid tolerance and result finally in a downregulation of opioid system functions (Chakrabarti et al., 2001). It is possible that the changes in the opioid system during the development of morphine tolerance may contribute to the attenuation of CGRP-induced antinociception.

Morphine tolerance may not only trigger the change of antinociceptive effect of CGRP through the opioid system, but also through acting on the CGRP system itself. The relationship between changes of CGRP-like immunoreactivity and morphine tolerance has been reported previously. Gardell et al. (2002) demonstrated that sustained morphine induced both the content and the evoked release of CGRP in both primary afferents and the spinal cord. Studies have demonstrated an upregulation of CGRP-like immunoreactivity in the spinal dorsal horn 
Fig. 5. Plasticity of CGRP-like immunoreactivity in the brain after morphine tolerance. A,C,E,G: Expression of CGRP in LS, CeA, ARC, PAG in opioidnaive rats. $\mathbf{B}, \mathbf{D}, \mathbf{F}, \mathbf{H}$ : Expression of CGRP in LS, CeA, ARC, PAG in morphine-tolerant rats. CGRP, calcitonin gene-related peptide; LS, lateral septal nucleus; CeA, central nucleus of amygdala; ARC, arcuate nucleus of hypothalamus; PAG, periaqueductal gray. Scale bar $=100 \mu \mathrm{m}$.

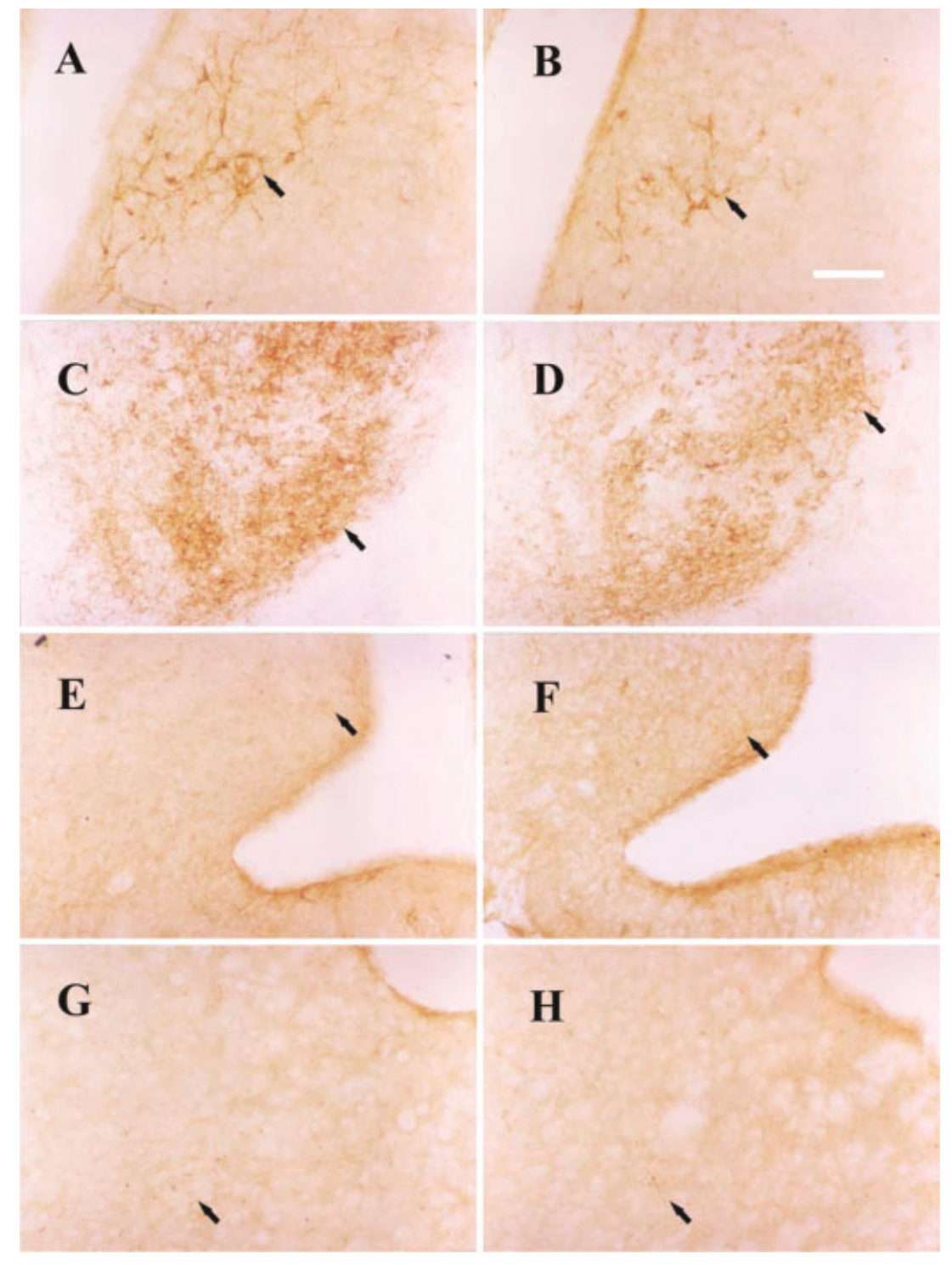

during the development of morphine tolerance and in the cultured dorsal root ganglion neurons after morphine treatment (Menard et al., 1995a,b; Ma et al., 2000). Further investigations by this research group indicated that after treatment with any $\mu, \kappa$, and $\delta$ agonist, the number of dorsal root ganglion (DRG) neurons with CGRP-like immunoreactivity increased significantly with a concentration-dependent manner (Belanger et al., 2002). As a support, another report showed that the levels of CGRP in the spinal cord were increased at $2 \mathrm{hr}$ and recovered to normal at $24 \mathrm{hr}$ after the final injection (Nylander et al., 1991). Conflicting results also occurred, however, as some studies reported that there was no alternation of CGRP levels at the spinal levels after morphine tolerance (Welch et al., 1992). These disparate data suggested that the CGRP levels in morphine treatment might depend on procedural differences, treatment duration, and the dose of morphine used, and thus implicated the complication of morphine tolerance as previous studies have shown (Yoburn et al., 1990). On the other hand, a few studies have focused on the role of CGRP at the supraspinal levels during morphine tolerance. Welch et al. (1992) reported that tolerance to morphine did not alter the CGRP levels in the rat brain assessed by radioimmunoassay. Studies using the same method also showed that subchronic exposure to morphine elevated the content of CGRP in the medulla oblongata, whereas no alteration occurred in the hypothalamus and midbrain (Tiong et al., 1992). No tests of CGRP-like immunoreactivity in specific nuclei of brain, however, were conducted in those studies. In the present study, immunohistochemical results showed significant decreases in CGRP-like immunoreactivity in both LS and CeA in rats with morphine treatment, whereas no changes in the ARC of hypothalamus and PAG were observed. The results in the ARC of hypothalamus and PAG are somewhat consistent with previous studies that the contents of CGRP in the midbrain and hypothalamus were not altered (Tiong et al., 


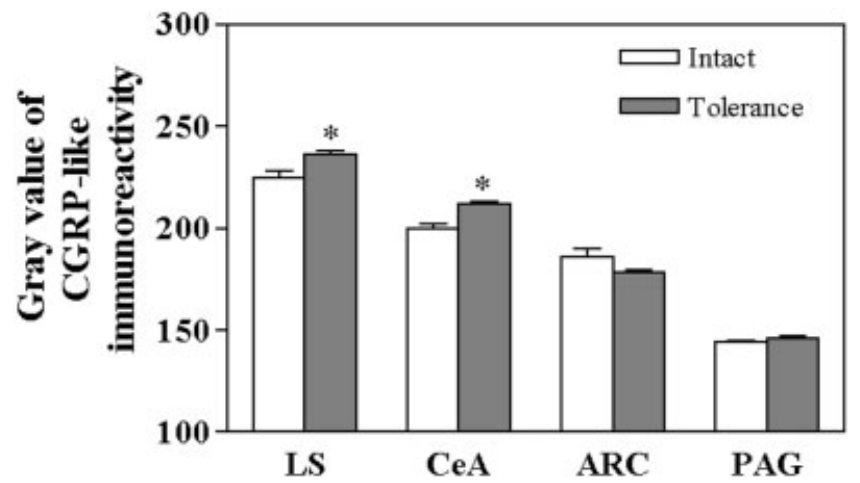

Fig. 6. Gray value of CGRP-like immunoreactivity in different brain regions after morphine tolerance. Gray value is expressed on a 256-level gray scale $(0=$ pure black; $255=$ pure white). Data are presented as mean \pm SEM. Statistical difference between groups was determined by Student's two-tailed $t$-test, ${ }^{\star} P<0.05, \star \star P<0.01$, and $\star \star \star P<0.001$ compared to control group. CGRP, calcitonin gene-related peptide; LS, lateral septal nucleus; CeA, central nucleus of amygdala; ARC, arcuate nucleus of hypothalamus; PAG, periaqueductal gray.

1992; Welch et al., 1992). Our results suggested strongly that there might be a downregulation of CGRP in several brain regions during development of morphine tolerance. It is possible that the plastic changes in CGRP-like immunoreactivity in the rat brain during morphine tolerance contributed to the change in CGRP function at the supraspinal level.

In conclusion, the results of the present study demonstrated that there was downregulation in CGRPinduced antinociception, which is possibly resulted from the changes in both the opioid and the CGRP systems. The latter was implicated partly in the present study, in that there were plastic changes in CGRP-like immunoreactivity in rat brain after morphine tolerance. All results above suggested that CGRP might play an important role in morphine tolerance.

\section{ACKNOWLEDGMENT}

We thank Prof. T. Lundeberg (Karolinska Institutet, Sweden) for the gifts of CGRP and antibody against CGRP.

\section{REFERENCES}

Azarov AV, Szabo G, Czako L, Telegdy G. 1995. Effects of calcitonin gene-related peptide on acute and chronic effects of morphine. Pharmacol Biochem Behav 52:595-599.

Ballet S, Mauborgne A, Benoliel JJ, Bourgoin S, Hamon M, Cesselin F, Collin E. 1998. Polyarthritis-associated changes in the opioid control of spinal CGRP release in the rat. Brain Res 796:198-208.

Bao L, Jin SX, Zhang C, Wang LH, Xu ZZ, Zhang FX, Wang LC, Ning FS, Cai HJ, Guan JS, Xiao HS, Xu ZQ, He C, Hokfelt T, Zhou Z, Zhang X. 2003. Activation of delta opioid receptors induces receptor insertion and neuropeptide secretion. Neuron 37:121-133.

Belanger S, Ma W, Chabot JG, Quirion R. 2002. Expression of calcitonin gene-related peptide, substance $\mathrm{P}$ and protein kinase $\mathrm{C}$ in cultured dorsal root ganglion neurons following chronic exposure to $\mathrm{mu}$, delta and kappa opiates. Neuroscience 115:441-453.

Candeletti S, Ferri S. 1990. Antinociceptive profile of intracerebroventric- ular salmon calcitonin and calcitonin gene-related peptide in the mouse formalin test. Neuropeptides 17:93-98.

Chakrabarti S, Oppermann M, Gintzler AR. 2001. Chronic morphine induces the concomitant phosphorylation and altered association of multiple signaling proteins: a novel mechanism for modulating cell signaling. Proc Natl Acad Sci USA 98:4209-4214.

Collin E, Frechilla D, Pohl M, Bourgoin S, Le Bars D, Hamon M, Cesselin F. 1993. Opioid control of the release of calcitonin gene-related peptidelike material from the rat spinal cord in vivo. Brain Res 609:211-222.

Doods H, Hallermayer G, Wu D, Entzeroth M, Rudolf K, Engel W, Eberlein W. 2000. Pharmacological profile of BIBN4096BS, the first selective small molecule CGRP antagonist. Br J Pharmacol 129:420-423.

Gardell LR, Wang R, Burgess SE, Ossipov MH, Vanderah TW, Malan TP Jr, Lai J, Porreca F. 2002. Sustained morphine exposure induces a spinal dynorphin-dependent enhancement of excitatory transmitter release from primary afferent fibers. J Neurosci 22:6747-6755.

Huang YH, Brodda-Jansen G, Lundeberg T, Yu LC. 2000. Antinociceptive effects of calcitonin gene-related peptide in nucleus raphe magnus of rats: an effect attenuated by naloxone. Brain Res 873:54-59.

Li N, Lundeberg T, Yu LC. 2001. Involvement of CGRP and CGRP1 receptor in nociception in the nucleus accumbens of rats. Brain Res 901:161-166.

Ma W, Zheng WH, Kar S, Quirion R. 2000. Morphine treatment induced calcitonin gene-related peptide and substance $\mathrm{P}$ increases in cultured dorsal root ganglion neurons. Neuroscience 99:529-539.

Menard DP, van Rossum D, Kar S, Jolicoeur FB, Jhamandas K, Quirion R. 1995a. Tolerance to the antinociceptive properties of morphine in the rat spinal cord: alteration of calcitonin gene-related peptide-like immunostaining and receptor binding sites. J Pharmacol Exp Ther 273:887-894.

Menard DP, van Rossum D, Kar S, Quirion R. 1995b. Alteration of calcitonin gene related peptide and its receptor binding sites during the development of tolerance to mu and delta opioids. Can J Physiol Pharmacol 73:1089-1095.

Menard DP, van Rossum D, Kar S, St Pierre S, Sutak M, Jhamandas K, Quirion R. 1996. A calcitonin gene-related peptide receptor antagonist prevents the development of tolerance to spinal morphine analgesia. J Neurosci 16:2342-2351.

Morton CR, Hutchison WD. 1990. Morphine does not reduce the intraspinal release of calcitonin gene-related peptide in the cat. Neurosci Lett 117:319h-324.

Nylander I, Sakurada T, Le Greves P, Terenius L. 1991. Levels of dynorphin peptides, substance $\mathrm{P}$ and CGRP in the spinal cord after subchronic administration of morphine in the rat. Neuropharmacology 30:1219-1223.

Paxinos G, Watson C. 1998. The rat brain in stereotaxic coordinates, 4th ed. Sydney: Academic Press.

Pecile A, Guidobono F, Netti C, Sibilia V, Biella G, Braga PC. 1987. Calcitonin gene-related peptide: antinociceptive activity in rats, comparison with calcitonin. Regul Pept 18:189-199.

Powell KJ, Ma W, Sutak M, Doods H, Quirion R, Jhamandas K. 2000. Blockade and reversal of spinal morphine tolerance by peptide and nonpeptide calcitonin gene-related peptide receptor antagonists. Br J Pharmacol 131:875-884.

Salmon AM, Damaj MI, Marubio LM, Epping-Jordan MP, Merlo-Pich E, Changeux JP. 2001. Altered neuroadaptation in opiate dependence and neurogenic inflammatory nociception in alpha CGRP-deficient mice. Nat Neurosci 4:357-358.

Tiong GK, Pierce TL, Olley JE. 1992. Subchronic exposure to opiates in the rat: effects on brain levels of substance $\mathrm{P}$ and calcitonin gene-related peptide during dependence and withdrawal. J Neurosci Res 32:569-575. van Rossum D, Hanisch UK, Quirion R. 1997. Neuroanatomical localization, pharmacological characterization and functions of CGRP, related peptides and their receptors. Neurosci Biobehav Rev 21:649-678.

Welch SP, Bass PP, Olson KG, Pugh G. 1992. Morphine-induced modulation of calcitonin gene-related peptide levels. Pharmacol Biochem Behav 43:11070 -1116. 
Welch SP, Cooper CW, Dewey WL. 1988. An investigation of the antinociceptive activity of calcitonin gene-related peptide alone and in combination with morphine: correlation to $45 \mathrm{Ca} 2+$ uptake by synaptosomes. J Pharmacol Exp Ther 244:28-33.

Wu X, Wang DW, Zhang GH, Chen HF, Shan YM, Tao LY. 1999. The changes of GFAP, PCNA after brain contusion: an immunohistochemical study in forensic pathology. Fa Yi Xue Za Zhi 18:65-66.

Xu W, Lundeberg T, Li Y, Yu LC. 2003. Antinociception effect of calcitonin gene-related peptide in central nucleus of amygdala: activating opioid receptors through amygdala-periaqueductal gray pathway. Neuroscience 118:1015-1022.

Xu SL, Lundeberg T, Yu LC. 2000. Antinociceptive effects of calcitonin gene-related peptide injected into periaqueductal grey of rats with mononeuropathy. Brain Res 859:358 -360.

Yoburn BC, Lutfy K, Azimuddin S, Sierra V. 1990. Differentiation of spinal and supraspinal opioid receptors by morphine tolerance. Life Sci 46:343-350.
Yu LC, Hansson P, Brodda-Jansen G, Theodorsson E, Lundeberg T. 1996a. Intrathecal CGRP8-37-induced bilateral increase in hindpaw withdrawal latency in rats with unilateral inflammation. Br J Pharmacol 117:43-50.

Yu LC, Hansson P, Lundeberg T. 1994. The calcitonin gene-related peptide antagonist CGRP8-37 increases the latency to withdrawal responses in rats. Brain Res 653:223-230.

Yu LC, Hansson P, Lundeberg T. 1996b. The calcitonin gene-related peptide antagonist CGRP8-37 increases the latency to withdrawal responses bilaterally in rats with unilateral experimental mononeuropathy, an effect reversed by naloxone. Neuroscience 71:523-531.

Yu LC, Weng XH, Lundeberg T. 2003. Involvement of calcitonin generelated peptide and its receptor in antinociception in the periaqueductal grey of rats. Neurosci Lett 349:1-4.

Zimmermann M. 1983. Ethical guidelines for investigations of experimental pain in conscious animals. Pain 16:109-110. 